\section{The Barrie Jones Lecture-Eye care for the neglected population: challenges and solutions}

GN Rao and Moorfields historian Peter Leaver, 'He changed the direction of ophthalmic practice at Moorfields Hospital, transformed the relationship between clinicians and researchers and enhanced the reputation of the Institution' ${ }^{1}$ He went on to create the 'International Centre for Eye Health' and made it into a global epicentre of preventive ophthalmology. He did not confine himself to the work at the Centre but was actively involved in the field in several programmes, particularly focussed on trachoma, in many developing countries. Professor Jones was a rare combination of sharp intellect, limitless compassion, and boundless energy. Honours and awards, too numerous to mention, came from all parts of the world.

I am also grateful for this opportunity as my own professional career has some similarities in the path it has taken. I also believe that the topic I have chosen for this lecture would have found acceptance from Professor Jones, as he dedicated a better part of his life working to alleviate the suffering of neglected populations from the scourge of avoidable blindness.

\section{Neglected populations}

It is indeed a great privilege to deliver this lecture in honour of Professor Barrie Jones who was much admired worldwide for his outstanding qualities and contributions. Born in New Zealand, he moved to the United Kingdom after his medical education and early ophthalmology training. After a stellar career as a clinician-scientist, producing seminal work on multiple aspects of corneal disease, he moved into the less glamorous area of preventive ophthalmology. In the words of his colleague
The dictionary meaning of the word 'neglected' is 'to pay no attention or too little attention to, disregard or slight'. 'Neglected populations' constitute people living in urban slums and sections of rural and tribal areas; those from the lower socio-economic groups with low literacy; women and children; people with disabilities; and migrants and refugees from most parts of the world. They are either denied or receive very little appropriate quality of health care, and eye care is no exception. 
Economic deprivation is a fact of life in most developing countries and there are numerous pockets of extreme poverty in these countries. ${ }^{2}$ Typically, health care is most neglected among these people. Measures to alleviate poverty are showing some success in countries such as India. Extreme poverty, however, is a continuing reality in India. Rapid economic growth in recent years, coupled with supportive governmental policies, has significantly reduced the rate of poverty to $22 \%$ of the population or to 270 million people. ${ }^{2}$ However, this is still the largest concentration of poverty anywhere in the world.

McKinsey Global Institute's recent report ${ }^{2}$ argues that India's benchmark for extreme poverty, while fair, counts only those living in abject poverty. Employing a matrix of other human development indices, the report proposed a new index called 'empowerment line' rooted in sound economic methodology and utilizing published government data. ${ }^{2}$ This, according to the report, is a holistic measure of income-based deprivation, which is more widespread. It is an estimate of the minimum economic cost for a household to fulfil eight basic needs, namely, food, energy, housing, drinking water, sanitation, health care, education, and social security. ${ }^{2}$ Applying this metric for 2011-2012, some 680 million (56\% of population) would be classified as deprived. ${ }^{2}$ A further classification according to depth of poverty shows 57 million classified as 'excluded', 210 million 'impoverished', and 413 million 'vulnerable', making a total of 680 million. $^{2}$

All these categories of people carry a much greater risk for blindness and visual impairment. ${ }^{3-5}$ Lack of awareness, availability, accessibility, and affordability of services constitute major barriers for care. ${ }^{6-12}$

Compounding this is the likelihood of these people presenting with late-stage disease, often escalating the cost of care significantly. This further complicates both care and funding-related issues. The availability of reasonable information on the epidemiology of global blindness and visual impairment from many parts of the world has been very useful in effective planning and formulation of policy. This evidence is also a potent advocacy tool and facilitated the passage of favourable World Health Assembly resolutions giving appropriate priority for prevention of blindness. ${ }^{13-16}$

The World Health Report 2008, ${ }^{17}$ in response to a 'need to respond better-and faster-to the challenges of a changing world', discussed the various facets of primary health care. ${ }^{17}$ It has pointed out that 'good care is about people' and that as nations are looking to improve their health-care systems, primary health care is considered as a viable option. Person-centred care, comprehensive and integrated responses, continuity of care, and bringing a regular and trusted provider at entry points are critical to better health outcomes. ${ }^{17}$ Bringing care closer to people in settings that are in close proximity to people, giving primary care provider the responsibility of a defined population, and the role of coordination of inputs of other levels of care are also considered important. ${ }^{17}$

Many countries, both developed and developing, are engaged in rolling out plans for 'Universal Health Coverage' to all people. The High Level Expert Group on Universal Health Coverage ${ }^{18}$ that was constituted by the Planning Commission of India with a mandate of developing a framework for providing easily accessible and affordable health care to all Indians defined Universal Health Coverage as, 'Ensuring equitable access for all Indian citizens, resident in any part of the country, regardless of income level, social status, gender, caste or religion, to affordable, accountable, appropriate health services of assured quality (promotive, preventive, curative and rehabilitative) ${ }^{\prime} .{ }^{18}$ Elimination of avoidable blindness requires implementation of all these principles, particularly in the case of neglected populations.

In this paper, I will discuss the current situation of this major global public health problem, the case study of India and the Indian State of Andhra Pradesh. In addition, the pyramidal model of delivery of comprehensive and equitable eye care developed by L V Prasad Eye Institute (LVPEI) of India and how it addresses the issue of 'Universal Eye Health Coverage' for the neglected populations, embodying the principle of primary health care enunciated in World Health Report 2008 will be discussed.

\section{Global blindness}

Avoidable blindness and visual impairment are major public health problems globally. It is estimated that there are 32.4 million people with blindness and 191 million people with moderate severe visual impairment (MSVI) as per the figures of 2010. About $60 \%$ of those who are blind and $57 \%$ of those with MSVI are women. The global age-standardized prevalence of blindness and MSVI for older adults are $1.9 \%$ and $10.4 \%$, respectively. Even after adjusting for age, the prevalence of blindness is greater in women than men across the world. In all, $84.6 \%$ of people with blindness and $77.5 \%$ of those with MSVI are 50 years of age and older. Blindness and visual impairment are more common in the most populated countries such as India (8.3 million) and China (5.2 million). Of the global population with MSVI, 31\% live in India and another $17 \%$ live in China, followed by Pakistan and Indonesia. ${ }^{19}$ All these countries have large pockets of neglected population.

Cataract and uncorrected refractive errors remain the leading causes of blindness, and uncorrected refractive errors the leading cause of MSVI in the year $2010 .^{20}$ 
Cataract (33\%), uncorrected refractive error (21\%), and age-related macular degeneration $(7 \%)$ contribute to most blindness. Uncorrected refractive error (53\%), cataract $(18 \%)$, and age-related macular degeneration $(3 \%),{ }^{20}$ while being major contributors to MSVI, are generally showing a decreasing trend worldwide. $^{20}$

Although the initial global blindness prevention programmes focussed on causes that are largely in the domain of public health programmes such as Trachoma, Onchocerciasis, and Vitamin A deficiency, the focus has shifted to add cataract in recent years. ${ }^{21}$ Success stories abound in the control of vitamin A deficiency, ${ }^{22,23}$ onchocerciasis, $^{24-26}$ and trachoma. ${ }^{27,28}$ Better understanding of the underlying mechanisms of the disease, epidemiology, pharmacology, and surgical techniques have contributed to this phenomenon. Global partnerships, multisectoral collaboration, public-private partnerships, corporate philanthropy, support from non-governmental organizations-both local and international-and governments are responsible for the success of these programmes. ${ }^{22,23,25-29}$ The philanthropic support through unlimited donation of ivermectin by Merck and azithromycin by Pfizer are outstanding examples of public-private partnership that was pivotal for effective control of onchocerciasis and trachoma.

Blinding onchocerciasis was virtually eliminated from Latin America by 2012 as well as in some pockets of Africa. ${ }^{30-32}$ Trachoma is nearing extinction in countries such as Morocco, Ghana, Mexico, Oman, and Saudi Arabia, ${ }^{33}$ while some other countries are approaching their target dates for elimination. ${ }^{29,33}$ Access to more resources through their inclusion in the group of 'neglected tropical diseases' further promotes their chance of elimination.

While the success so far is limited to blinding conditions that can be tackled through wide-spread public health approaches, no other cause of blindness or visual impairment has had a similar record.

\section{Cataract and refractive errors}

Cataract surgery is one of the most cost-effective interventions in health care, ${ }^{34,35}$ while refractive errors can be corrected using spectacles. Although solutions for these appear simple, the challenge is to scale them to a global level. Some viable models for delivery of cataract surgical care have been developed in India and other countries for large-scale and relatively successful interventions. ${ }^{36-41}$ The issues of access, affordability, and availability continue to plague health systems in many countries, and in the more successful cases, outcomes are a cause for concern. ${ }^{37,42-44}$ Various financing mechanisms used in countries such as Brazil, India, China, Mexico, and other countries have contributed towards the creation of fairly robust models for delivery of cataract surgical care. ${ }^{37}$

The situation has improved recently in India after the adoption of a focussed approach to tackle the problem of cataract in all its dimensions. ${ }^{45}$ Governmental commitment, including significant infusion of funding initially through the assistance of World Bank succeeded by further allocation of internal funds, has made an impact. ${ }^{46,47}$ Strengthening of infrastructure and training of all cadres of human resources contributed to this positive change. The volume of cataract surgeries almost tripled over the past two decades and the outcomes have improved. ${ }^{47}$ Over 6.3 million cataract surgeries were conducted in year 2012-2013. ${ }^{48}$ Previous evidence of poor outcomes has led to greater focus on quality and some measures were initiated by the national programme. These include the provision of better equipment; training of surgeons in intraocular lens implantation; greater adaption of modern cataract surgical techniques; and better follow-up, which together have had a salutary effect on the final outcomes of cataract surgery across the country.

Several approaches for addressing the issue of uncorrected refractive error are being tested in different parts of the world. ${ }^{49}$ These include the LVPEI's pyramidal model with vision centres at the primary level and its variants, as practiced by other non-governmental organizations in India and other developing countries of the world. The Indian Government has allocated significant funding for the development of 4000 vision centres and so has the Australian Government's 'Avoidable Blindness Initiative' that targets blindness in South East Asia. The social entrepreneur models use the rural microfinancing model for the dispensing of spectacles such as those run by VisionSpring (formerly Scojo Foundation) in Latin America and parts of Asia. ${ }^{50}$ The ICEE (International Centre for Eyecare Education, presently Brien Holden Vision Institute Foundation) Vision Centre model and the Optical Centre model of West Africa are other INGO-based eye care models for uncorrected refractive errors and presbyopia. ${ }^{49,51}$ District health models used by many government health systems provide multi-level eye care, but often lack the appropriate infrastructure and appropriately trained human resources as well as referral linkages. ${ }^{51}$ A major barrier for many of these is the timely supply of affordable spectacles to the remote geographic areas.

\section{Emerging challenges}

Adding to the global burden of cataract and refractive errors are the emerging challenges of diabetic 
retinopathy (DR), glaucoma, childhood blindness from various causes, and issues related to low vision care. ${ }^{20}$ There are no clearly defined public health approaches for any of these and currently all of these are in the realm of tertiary care.

For DR, a number of approaches are currently under investigation. ${ }^{52,53}$ Greater public awareness, health education, detection, and control of diabetes were all shown to have salutary effects in minimizing the development of DR. While there is ample evidence that early detection and laser therapy can control blindness from DR, there is severe limitation of access and affordability in most parts of the world..$^{52}$ In a majority of the developing countries, diabetic eye care does not exist in isolation and opportunistic screening remains the predominant model. ${ }^{54}$

Glaucoma is recognized as one of the major causes of blindness in recent years. Currently, the best approach to manage glaucoma in developing countries is case detection through opportunistic screening and comprehensive eye examination at all levels of care. ${ }^{55}$ Studies have shown that a vision technician at a vision centre could detect $68 \%$ of subjects presenting with significant ocular disease. Addition of frequency doubling perimeter examination at the vision centre increased the sensitivity for vision technician disease detection by $20 \%$ including detection of glaucoma. ${ }^{56}$

Childhood blindness is one of the most neglected areas of eye care in developing countries. The blindness in children in economically developed countries and regions, such as the United States, Canada, Western Europe, and Japan, is $0.3-0.4$ per 1000 children. In the Western Pacific region, the prevalence is estimated at $0.2-0.7$ per 1000; and in Asia, 0.9 per 1000 . In very lowincome countries the prevalence is about 1.2 per $1000.57,58$ Cataract, corneal scar, retinopathy of prematurity, glaucoma, retinal dystrophies, and retinoblastoma form the gamut of conditions that contribute to most of the blindness. ${ }^{57,58}$

About 80 million people worldwide have low vision, ${ }^{19,20}$ with this number set to increase with ageing population. Based on the data from Andhra Pradesh Eye Disease Study, one in every hundred persons had low vision, associated mainly with old age and lower socioeconomic status. ${ }^{59}$ Major causes of low vision included retinal diseases $(35.2 \%)$, amblyopia (25.7\%), optic atrophy $(14.3 \%)$, glaucoma (11.4\%), and corneal diseases $(8.6 \%)$. Low vision care, initially a hospital-based service, focussed on dispensing optical and non-optical devices, eventually evolved into a multidisciplinary holistic rehabilitative approach. ${ }^{60}$ However, these services are still inadequate in many areas. ${ }^{61}$ It is estimated that only $5-10 \%$ of the people needing low vision services access it with huge variation between regions and countries. ${ }^{61}$ With the recent technological advances, better access to appropriate low vision care can now be made available to neglected populations.

\section{Blindness in India}

India has the largest magnitude of blindness and visual impairment in the world, in numbers disproportionate to its proportion of global populations (8.3 million in 2010). ${ }^{19}$ Indeed, India's National Programme for Control of Blindness was the first such national endeavour focussing on blindness when it was launched in $1976 .{ }^{62}$ This national commitment had a significant long-lasting impact on the control of blindness. While notable progress has been made in controlling this in the past two to three decades, much still needs to be done to control blindness effectively across the entire country.

India has undertaken epidemiologic surveys using rapid assessment methodology to get an estimate of the prevalence of blindness on a national scale. These studies are undertaken among those aged 50 years and older. A survey conducted in 2008 has shown a blindness prevalence of $3.6 \%$ compared with $5.3 \%$ in 1999-2000 and $5.2 \%$ in 1998. ${ }^{63-65}$ Major causes of blindness in this group included uncorrected refractive error, cataract, surgical complications, aphakia, corneal scars, and DR with cataract constituting the major portion of the problem. The rate of blindness was significantly higher among people from lower socio-economic backgrounds and women. ${ }^{64}$ The rate was also higher among residents of rural areas compared with urban areas. ${ }^{64}$ In addition, significant disparity existed among different states of India and among the various districts in the same state. ${ }^{66}$

The prevalence of cataract blindness showed a downward trend over the past three decades. The absolute number of cataract blind, however, will increase because of the escalation in the population aged 50 years and above, increasing from 7 to 7.5 million in 2001 to 8.25 million in 2020.66 With these projections and the current sight restoration rate after cataract surgery, the elimination of cataract blindness is unlikely in India by the year 2020. ${ }^{66}$

While India has shown substantial progress in the area of cataract surgery, both in volume and quality, much needs to be done in tackling other causes of blindness and visual impairment. ${ }^{63,66}$

\section{Blindness in Andhra Pradesh}

An epidemiologic cross-sectional study titled 'Andhra Pradesh Eye Disease Study (APEDS)' was undertaken using a stratified random cluster systematic sampling 
strategy. ${ }^{67}$ Currently, the follow-up of the surviving cohort of APEDS 1 is underway to study the incidence (among non-cases) and progression (among cases) of eye diseases in three rural locations.

It was found that age, gender, and urban-rural distribution adjusted prevalence of blindness (presenting distance visual acuity $<6 / 60$ or central visual field $<20^{\circ}$ in the better eye) was $1.84 \%$ (95\% CI, 1.49-2.19\%). ${ }^{68}$ Most of the causes of this blindness were easily treatable in $60.3 \%$ (cataract, $44 \%$; refractive error, $16.3 \%$ ) of the cases, ${ }^{68}$ while preventable corneal disease, glaucoma, complications of cataract surgery, and amblyopia contributed to another $19 \%$ of the blindness. ${ }^{68}$

As for moderate visual impairment, the adjusted prevalence of moderate visual impairment (presenting distance visual acuity $<6 / 18$ to $6 / 60$ or equivalent visual field loss in the better eye) was $8.09 \%$ (95\% CI, 6.89-9.30\%). ${ }^{69}$ Uncorrected refractive errors were the leading cause $(45.8 \%)$ and cataract $(39.9 \%)$ was the second most common cause. ${ }^{69}$ The causes of blindness and moderate visual impairment are summarized in Table 1.

In the case of refractive errors, among those aged 15 years and older, $3.19 \%$ and $62.62 \%$ had myopia and hyperopia, respectively. ${ }^{70}$ The issue of usage of spectacles was also considered. Among those aged $>15$ years, the prevalence of current use of spectacles in those with spherical equivalent $\pm 3.00 \mathrm{D}$ or worse, and who were likely to be visually impaired without refractive correction, was 34.2\% (95\% CI, 30.3-38\%) and of previous use of spectacles was $12.3 \%$ (95\% CI, 10.3-14.3\%). ${ }^{71}$ Among those who had used spectacles previously, $43.8 \%$ had discontinued use

Table 1 Causes of blindness and moderate visual impairment-Andhra Pradesh Eye Disease Study

\begin{tabular}{lcc}
\hline Cause & $\begin{array}{c}\text { Blindness } \\
\text { (presenting } \\
\text { visual acuity } \\
\text { worse than 6/60 } \\
\text { in the better } \\
\text { eye) }\end{array}$ & $\begin{array}{c}\text { Moderate visual } \\
\text { impairment } \\
\text { (presenting } \\
\text { visual acuity } \\
<6 / 18 \text { to } 6 / 60 \text { in } \\
\text { the better eye) } \\
(\%)\end{array}$ \\
\hline Cataract & 44 & 39.9 \\
Uncorrected refractive errors & 16.3 & 45.8 \\
Retinal disease & 10.9 & 3.4 \\
Glaucoma & 8.2 & 1 \\
Corneal disease & 7.1 & 2.3 \\
Optic atrophy & 6 & 1.8 \\
Amblyopia & 4.3 & 2.7 \\
Congenital eye anomaly & 1.1 & - \\
Others & 2.2 & 3.1 \\
\hline
\end{tabular}

because they felt that either the prescription was incorrect or that the spectacles were uncomfortable, suggesting poor quality of refractive services, and another $19.6 \%$ had lost their spectacles and could not afford to replace them. ${ }^{71}$

The relatively poor usage of spectacles in this population by those with refractive error to begin with as well as discontinuation of use are significant issues that need to be tackled in planning refractive services in future.

Visual outcomes after cataract surgery were among the most significant observations of this study. In the population-based sample, of the 129 operated eyes, $51(39.5 \%)$ were blind after surgery, which included $41(31.8 \%)$ from cataract surgery-related causes. ${ }^{42}$ Of the 106 persons in the population sample who had had cataract surgery in one or both eyes, 26 (24.5\%) remained blind. ${ }^{42}$ In contrast, when the outcomes at two of the rural eye centres were studied, $3.1 \%$ of the eyes and $1.8 \%$ of the persons were blind after surgery, ${ }^{42}$ clearly highlighting that attention to quality yields desirable results.

From the data, it is very clear that in the southern state of Andhra Pradesh in India, the main problems of blindness are cataract, uncorrected refractive errors, corneal opacities, DR, and glaucoma. Using this information as the base and employing the principles of comprehensive, high-quality, equitable care to all people, a multi-tier model of eye care delivery was developed at LVPEI with a focus on the most vulnerable of the population in the remote, rural, and tribal areas.

\section{LVPEI model}

The Institute built on a system of high-quality, sustainable, comprehensive eye care to all people, commenced its operations in 1987 with its Centre of Excellence, with the vision of reconciling 'Excellence with Equity'. The rural eye care model developed in 1994 is a 'comprehensive eye care' system that encompasses health promotion, prevention, treatment, and rehabilitation. The model is also based on a commitment that everyone who needs care shall get it irrespective of the complexity and cost of care.

This model of eye care has evolved into a pyramidal structure with five tiers, which are clearly interlinked (Figure 1). ${ }^{39,72}$ It is comprehensive in terms of disease control, geographic and population coverage, services provided, delivery structures, linkages, and referrals. Reaching larger numbers, enhancing quality, making care equitable, sustainable, and employing an eye care team approach was the aim. Each member has a specific task for which appropriate training was given. Significant 


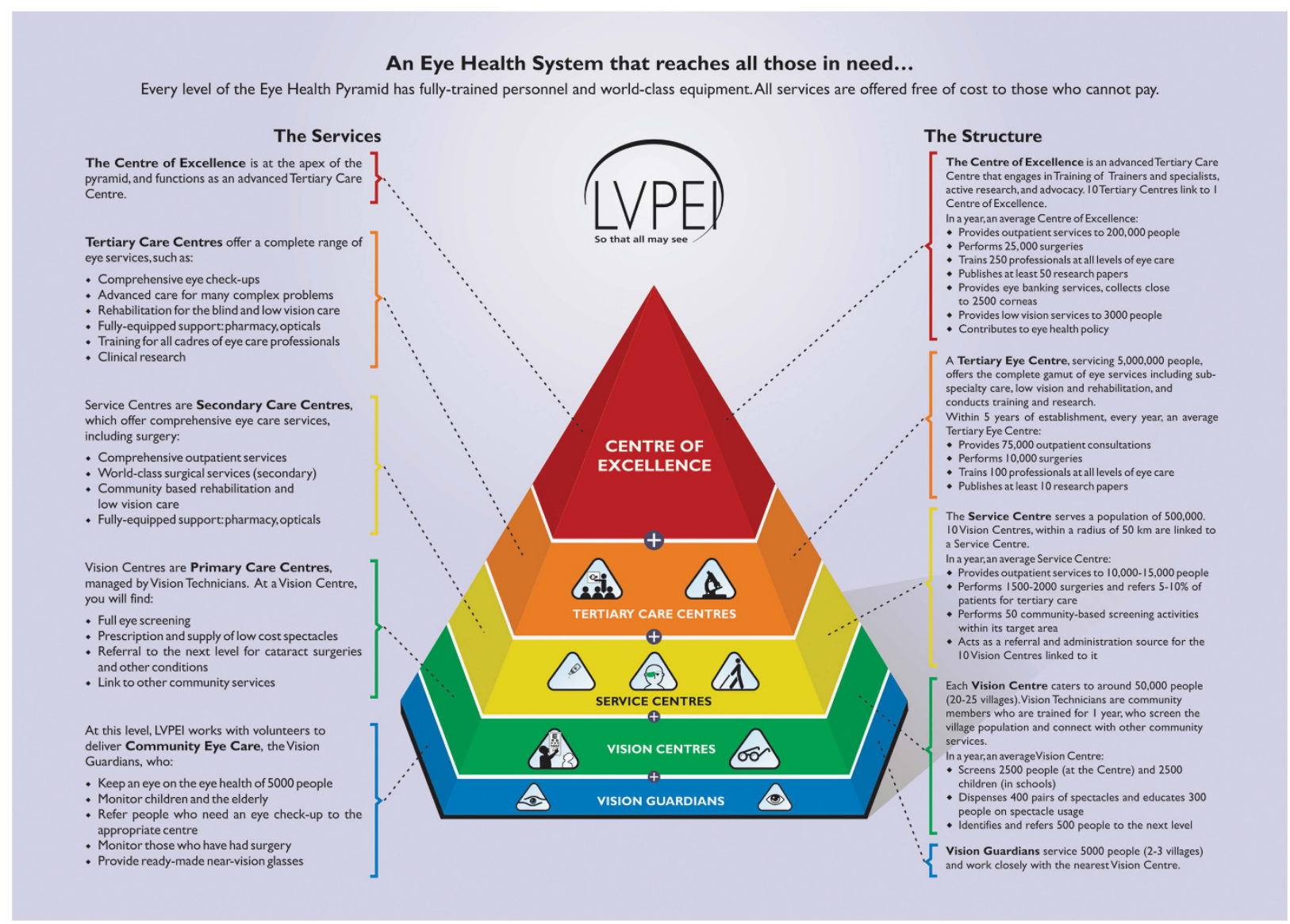

Figure 1 L V Prasad Eye Institute Pyramidal eye care service delivery model.

attention was given to achieving financial sustainability without neglecting the most neglected. Community participation along with linkage with general health care was emphasized.

This integrated multi-level system of eye care is based on the provision of appropriate care at each level, creation of good quality infrastructure, well-trained human resources, and employing proper operating systems. Many facets of technology, including ophthalmic information and communications technology, have begun to be incorporated recently. Most of the human resources are derived from the local communities, which further cements the community involvement. Need-based recruitment and training improves cost effectiveness. Competencies required for each task are identified and training is tailored to meet these requirements. Infrastructure is also designed matching the needs for each level of care without compromising quality. By eliminating needless expenditure on items that are not appropriate for a particular level of care, cost effectiveness was achieved. Physical space is organized creating a patient-centred ambience, and equipment used is of high quality.
Systems are put in place for proper upkeep of the entire infrastructure.

\section{Vision guardians}

At the bottom tier of the pyramid, for a population unit of 5000, local volunteers from the villages are identified and given the title 'Vision Guardians'. It is they who act as local representatives of the network. These people have basic school education, and keeping an 'eye on the eye health' of 5000 people is their main task. They are trained to provide eye health education with special attention to the vulnerable age groups-paediatric and geriatric-looking for people with potentially blinding diseases, providing surveillance for people who undergo eye surgery, and making readymade near vision glasses available. More recently, these vision guardians were also trained to screen the population for blood pressure and assessment of risk scores for diabetes, effectively making them eye health, diabetes, and hypertension educators for the community. ${ }^{39}$ This is the beginning of our efforts to address the 'causes of causes' of eye disease. ${ }^{73}$ 
The vision guardians and other cadres of field staff are involved in a number of community screening, eye health promotion, and public programmes. Those identified with any eye problems leading to visual impairment are referred for appropriate care either at the primary- or secondarylevel centres.

In one area with a population of about 46000,22 vision guardians screened about 40000 people and identified 4740 people with visual impairment. Spectacles were dispensed to about 1500 people and 700 people were operated on. Also, as a part of this initiative, 23 village health committees were formed and 33 vision gardens were developed. Vision gardens are home gardens where sweet potato tubers, papaya fruits, drumstick leaves, curry leaves, and so on are grown because they are nutritious and easy to grow. ${ }^{73}$ Table 2 shows the performance of the community eye care programmes during 2013-2014.

Yet another community-based eye care programme focusses on bringing about a behavioural change to increase the uptake of services at LVPEI's Secondary Centres. This project aims to promote community eye health with proper integration of Primary Eye Care services into existing Primary Health Care services. Typically, a target area with a population of 100000-120000 is selected and divided into clusters of 20000 each with two community eye health workers conducting door-to-door vision screening in the cluster. Till date, this project has covered 62 villages, reaching a population of 181942 at their doorstep. Over 14000 people have been identified with eye problems and surgeries were performed on over 2000 people. School eye health is an important activity of the community eye care programme. As part of this, school teachers are trained to conduct vision screening of the children in school. The performance of this programme during the year 2013-2014 is shown in Table 3.

\section{Vision centres}

The implementation of a new concept of a permanent primary eye care facility, appropriately equipped and staffed, in remote rural and tribal areas termed as 'Vision Centres', each covering a finite population of 50000 , constitutes the next level of the pyramid.

A typical vision centre is established in locations where there are no permanent ophthalmic services. The physical space is about $500-800 \mathrm{ft}^{2}$ and a central location in a village is selected. Easy access to the vision centres is one of the main criteria in the selection of a venue. Once the space is identified, it is designed to include a complete examination room with all equipment, a patient waiting area and optical outlet.

The vision centre system provides universal access to eye care for people living in remote communities. In response to the reality that very few ophthalmologists or fully trained optometrists are available to work in remote rural areas, these centres are staffed by technicians (high school graduates who receive a year of training). Their tasks include refraction and dispensing of spectacles, recognition of potentially blinding problems, and making

Table 3 Performance of school screening programme during year 2013-2014

\begin{tabular}{lr}
\hline Activity & Numbers \\
\hline School screening programmes organized & 259 \\
Children screened by trained teachers & 33989 \\
Examined by vision technician & 10521 \\
Prescribed with spectacles & 585 \\
Dispensed with spectacles & 532 \\
No. of children referred for eye examination & 1202 \\
\hline
\end{tabular}

Table 2 Performance of community screening during year 2013-2014

\begin{tabular}{lr}
\hline Activity & Numbers \\
\hline Slums/villages surveyed by community eye care personnel & 613 \\
Houses surveyed & 169557 \\
Population covered through door-to-door survey (vision screening at their doorsteps) & 590534 \\
People identified with eye problems and referred for management & 65272 \\
Community screening programmes organized & 731 \\
People examined by vision technicians & 70361 \\
Prescribed spectacles & 25769 \\
Dispensed spectacles & 11654 \\
Referred to base hospital & 14389 \\
No. of awareness (information, education, and communication) programs conducted & 101 (2865 participants) \\
Community-based rehabilitation for irreversibly visually impaired (includes training in orientation and & 690 \\
mobility skills and activities of daily living, economic rehabilitation, certification and assistance for pension, \\
travel concessions, scholarships, and other government services)
\end{tabular}


appropriate referrals. Uncorrected refractive errors, which constitute the second major cause of blindness and the leading cause of visual impairment globally, can be tackled at this level. These technicians also work to build strong linkages with the local communities and other health-care and development programmes.

Low vision care that is possible at this level is being added to their responsibilities. This indeed is the point of first contact for eye care, and in many places where these centres are located this is the only health-care facility available.

The advantage of this concept is that this could be part of any system-governmental or non-governmental, for profit or not-for-profit. The one-time capital cost of setting up such a centre is about USD 12000. While services are provided at 'no cost' to the patients, sale of low-cost spectacles is the only source of income for vision centres. The cost recovery for operational costs in financial year 2013-2014 was 67\%. However, the coverage for all neglected groups is $100 \%$.

Through evaluation of the programmes several critical factors were identified for success that include training of vision technicians, a robust system of supply of spectacles, strong referral linkages, strong monitoring system, and community ownership. ${ }^{39,74-76}$ Several benefits have also been observed. These centres become the health-care outposts and thus the first level of contact in many remote rural areas, which results in significant savings to the beneficiaries and their families, and enhanced gender equity with increased utilization by women and young adults.

Several policy implications have also emerged with this model getting acceptance from the Government of India, the Avoidable Blindness Initiative of Australian Government, and several other institutions in India ${ }^{77-80}$ and other South Asian countries. Several international NGOs are replicating this in sub-Saharan Africa, Middle East, and Latin America. ${ }^{38,51,81}$

Additional application of modern technological tools, both for ophthalmic diagnosis as well as information and communications technology, will enhance the ability to filter out the people who need to travel to centres for additional or advanced care.

Another small but significant contribution is towards rural development through the recruitment of vision technicians. This cadre also has career advancement opportunities through optometry, public health, and management.

Out of 108 vision centres till date, 23 centres are located in tribal and remote rural locations. The monthly screening numbers at vision centres range from about 60 to over 550 patients, with $20-150$ of them getting spectacles prescribed. There are several reasons for the low performance at some of the vision centres. While some are related to the very location of the centre such as remote rural or tribal location where people have very different health-seeking behaviour, other reasons could be because of issues related to vision technicians. Intensive information and health education campaigns and door-to-door visits are conducted in the communities where performance is low because of location issues. Transfer of vision technicians, retraining, and close monitoring and mentoring is provided.

The support team comprises of a Vision Centre coordinator, a technician to supply spectacles, central vision centre administrator, the administrator of secondary centre, and the optometrist who monitors and mentors. This helps in the smooth functioning as well as quality assurance of these centres.

Over the past 15 years of working with this concept, many lessons have been learnt and appropriate modifications have been made. These include factors such as population profile and consequent modifications, training of technicians, supply of spectacles, and patient perception. We have also become better in the selection of locations, changes in the curriculum of the technician training, and optical labs in the proximity of vision centres, resulting in lower cost to the patient. Another very encouraging development has been the increasing community support in the form of outright donation of space or property or rent-free space; helping in awareness campaigns; and subsidizing the costs of the centre for a certain period of time. This phenomenon has essentially reduced the dependence on international funding and augurs well for the future of health care. The performance of vision centres during year 2013-2014 is shown in Table 4. Table 5 compares the high- and low-performing vision centres during year 2013-2014.

Table 4 Performance of the vision centres during year 2013-2014

\begin{tabular}{lrrrrr}
\hline $\begin{array}{l}\text { Location of the } \\
\text { vision centre }{ }^{\mathrm{a}, \mathrm{b}, \mathrm{c}}\end{array}$ & $\begin{array}{r}\text { Number } \\
\text { of people } \\
\text { screened }\end{array}$ & $\begin{array}{c}\text { Number of } \\
\text { people } \\
\text { prescribed } \\
\text { with } \\
\text { spectacles }\end{array}$ & $\begin{array}{c}\text { Number } \\
\text { of people } \\
\text { dispensed } \\
\text { with } \\
\text { spectacles }\end{array}$ & $\begin{array}{c}\text { Number of } \\
\text { people } \\
\text { referred to } \\
\text { higher } \\
\text { centres for } \\
\text { management }\end{array}$ & $\begin{array}{c}\text { Cost } \\
\text { recovery } \\
(\%)\end{array}$ \\
\hline Tribal (15) & 22019 & 7676 & 6376 & 5471 & 79 \\
Remote-rural (8) & 8321 & 3218 & 2229 & 1917 & 60 \\
Rural (65) & 81559 & 26731 & 19167 & 18265 & 64 \\
Semi-urban (8) & 12668 & 4747 & 3136 & 3306 & 73 \\
Urban (3) & 9683 & 4240 & 2462 & 1747 & 138 \\
Total (99) & 134250 & 46612 & 33370 & 30706 & 69 \\
\hline
\end{tabular}

${ }^{a}$ Nine VCs are being shifted to new locations; total vision centres $=99$ $+9=108$ as on April 2014.

${ }^{\mathrm{b}}$ Five of these centres were inaugurated in April 2014.

'Sixteen of the centres are $<1$ year old. 
Table 5 Comparison of high- and low-performing vision centres during year 2013-2014

\begin{tabular}{lcc}
\hline Parameters & $\begin{array}{c}\text { High- } \\
\text { performing } \\
\text { vision centre }\end{array}$ & $\begin{array}{c}\text { Low- } \\
\text { performing } \\
\text { vision centre }\end{array}$ \\
\hline Location (village) $^{\mathrm{a}}$ & Pedandipadu & Kodepi \\
Total number screened & 6852 & 749 \\
Spectacles prescribed & 1763 & 178 \\
Spectacles dispensed & 1671 & 115 \\
Referral for higher centres management & 744 & 203 \\
Cost recovery (\%) & 150 & 25 \\
\hline
\end{tabular}

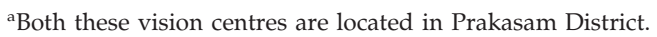

${ }^{\mathrm{b}}$ Sale of low-cost spectacles is the only source of income at vision centres.

\section{Recent additions to vision centres}

Integration of general health and eye screening at vision centre

This project aimed to integrate diabetes and hypertension screening with eye health care at the vision centres and ascertain whether there was any increased utilization of vision centres activities by the rural communities. In this project, nearly 20 vision centres have been upgraded as rural health posts to include equipment for measuring blood sugar and blood pressure. As of date, nearly 600 people were screened for diabetes and 6000 people were screened for high blood pressure.

\section{Telemedicine}

In some of our centres, telemedicine was introduced but only with moderate success owing to issues of connectivity in remote rural areas.

\section{Electronic medical records}

In the most recent centres, electronic medical records were introduced and this promoted greater degree of integration with vision centres.

\section{Vision centre plus}

With increasing demand and availability of local support, secondary care services such as cataract surgery was started by adding an operating room at one of our vision centres.

\section{Diabetes prevention and capacity building programme}

A programme based on preventive approach using children as volunteers for health promotion and health education on lifestyle changes for preventing diabetes was introduced. Children were trained to screen and identify high-risk individuals in the community.
This programme covered over 670 schools and 120000 children were trained. These children were able to reach over 0.5 million families and screened 2.4 million individuals, out of which 76000 people were indentified with high risk for diabetes (unpublished data). The children acted as vision guardians in this programme.

Yet another model for screening of DR at vision centres and in the community is by using a low-cost nonmydriatric fundus camera. This pilot project was implemented in one village vision complex consisting of a secondary centre and a cluster of 10 vision centres. As a part of this project, over 25 vision guardians were trained and over 260 screening programmes were organized among those with diabetes till date. More than 7000 individuals were examined using a non-mydriatic fundus camera and nearly 900 people were identified with DR (unpublished data).

The aspirations for primary health care expressed in the World Health Report of 2008, namely, entry points in proximity to people, continuity of care, and care to a defined population by putting 'people first', were indeed very much part of the concept of primary eye care of our pyramidal system. ${ }^{17}$

\section{Secondary service centres}

Those problems that cannot be addressed at the vision centre level require both additional competencies and infrastructure. This is provided through the secondary service centres. Linkage of primary care vision centres to 'secondary care service centre' is critical for the success of this programme. Typically, the vision centres are within a $50 \mathrm{kme}$ radius, and where the density of population is low, the distances may be longer. ${ }^{72}$

These centres provide oversight and support for vision centres and provide care for a significant proportion of eye conditions detected or suspected at the vision centre level such as cataract, glaucoma, DR, infections, and some low vision care. An ophthalmologist is the leader of the eye care team at these centres. Recruitment of most of the staff from the local communities is a key ingredient of this model contributing to greater community ownership and participation.

LVPEI's foray into rural eye health started with the concept of secondary care service centres providing highquality comprehensive eye care to all people in rural areas with a team approach. Each centre is created to serve a population of 500000 , encompassing all components of comprehensive care-prevention, treatment, and rehabilitation. The physical design, human resource matrix, systems, and procedures are standardized and continually improved during the past nearly 18 years. 
These centres are equipped and staffed to provide all diagnostic care, surgical care at the secondary level, which is predominantly cataract surgery along with treatment for DR and glaucoma including laser therapy and detection and treatment of infections. These centres also provide low vision services and coordinate community-based rehabilitation programmes. By providing care for all the problems including cataract, the rural population gets coverage for a broader range of eye problems. Apart from a completely non-paying category, a multi-tier paying system is practiced to cater to the needs of different economic groups. In all categories, the service provided will be identical, while amenities differ as per paying status.

This promotes greater access and affordability, and minimizes the need to travel to tertiary care centres in the cities, and the cost savings are immense. Each of these centres is equipped to provide outpatient services to 20000-30000 people and surgical care for 3000-4000 people annually. If these centres are developed properly with necessary infrastructure and human resources, most of cataract and refractive errors can be tackled effectively along with part of glaucoma, DR, corneal infections, and low vision problems, which together contribute to 75$90 \%$ of blindness.

It is evident from Table 6 that even at this level, a large segment of the neglected population below the 'empowerment line' are provided care with nearly twothirds of surgical procedures provided at no cost and about $58 \%$ of surgical procedures performed on women. Table 7 shows the comparison of two high- and lowperforming secondary centres. Table 8 provides the overview of human resources used in a typical secondary centre. $^{76,82}$

Table 6 Performance of secondary centres in year 2012-2013

\begin{tabular}{lccc}
\hline & $\begin{array}{c}\text { Total } \\
\text { seen }\end{array}$ & $\begin{array}{c}\text { Non-paying } \\
(\%)\end{array}$ & $\begin{array}{c}\text { Women } \\
(\%)\end{array}$ \\
\hline Outpatients & 138917 & 43.3 & 50.0 \\
Surgeries & 18919 & 68.3 & 57.8 \\
Overall cost recovery $(\%)^{\mathrm{a}}$ & 87 & & \\
\hline
\end{tabular}

abed on revenue generated from patient care services; does not include revenue from optical sales.
There are 11 secondary centres of LVPEI, several others which LVPEI helped with the development, and four more in the pipeline.

The entire integrated model from vision health guardians and encompassing a cluster of 10 vision centres providing primary eye care along with a secondary service centre is termed as 'Village Vision Complex', each serving 100-200 villages directly. ${ }^{39}$ (Figure 2) One of the important factors for success of village vision complex is the quality of human resources and strong linkage to a training and resource centre.

Without doubt, this programme has succeeded in addressing the eye care needs of many categories of 'neglected population' below the 'empowerment line'. This model also demonstrated the practical implementation of WHO's aspirations for primary health care. By taking high-quality care closer to people, much of the difficulty related to access has been eliminated, which promoted greater equity in care across gender, age groups, and socio-economic strata.

The success of the rural health initiative through the creation of 'Village Vision Complexes' is also dependent on the support available from the top tiers of this pyramidal model. The connection to the tertiary centres affords all tertiary level care for people who cannot be treated at the secondary level. In addition, most of the human resource requirements are met by the education and training programmes, as well as continuing education offered at the Tertiary Centres and Centres of Excellence. Another critical input comes from planning, resource mobilization, and overall administrative and quality monitoring. On rare occasions, some temporary staff shortages are filled from these centres.

\section{Tertiary training centres}

In India and other developing countries, as is evident from the epidemiologic data, there is significant burden of blindness caused by diseases that require complex care, demanding high levels of professional competence, technology, and equipment. This obviously makes the care more expensive. The LVPEI model is organized in a way that the smallest possible fraction of the blind and

Table 7 Comparison of high- and low-performing secondary centres during 2013-2014

\begin{tabular}{|c|c|c|}
\hline & High-performing centre & Low-performing centre \\
\hline Name of the centre & Navabharat Eye Centre, Paloncha, Khammam District & Swarna Bharat Eye Centre, Nellore District \\
\hline Outpatients seen & 24939 (non-paying 45\%) & 7640 (non-paying 75\%) \\
\hline Surgeries & 2956 (non-paying 69\%) & 1393 (non-paying 82\%) \\
\hline Income (in 000 INR) & 100.67 & 12.35 \\
\hline Expenditure (in 000 INR) & 84.33 & 36.22 \\
\hline Cost recovery $(\%)$ & 119.4 & 34.1 \\
\hline
\end{tabular}


Table 8 Human resources at the secondary centres

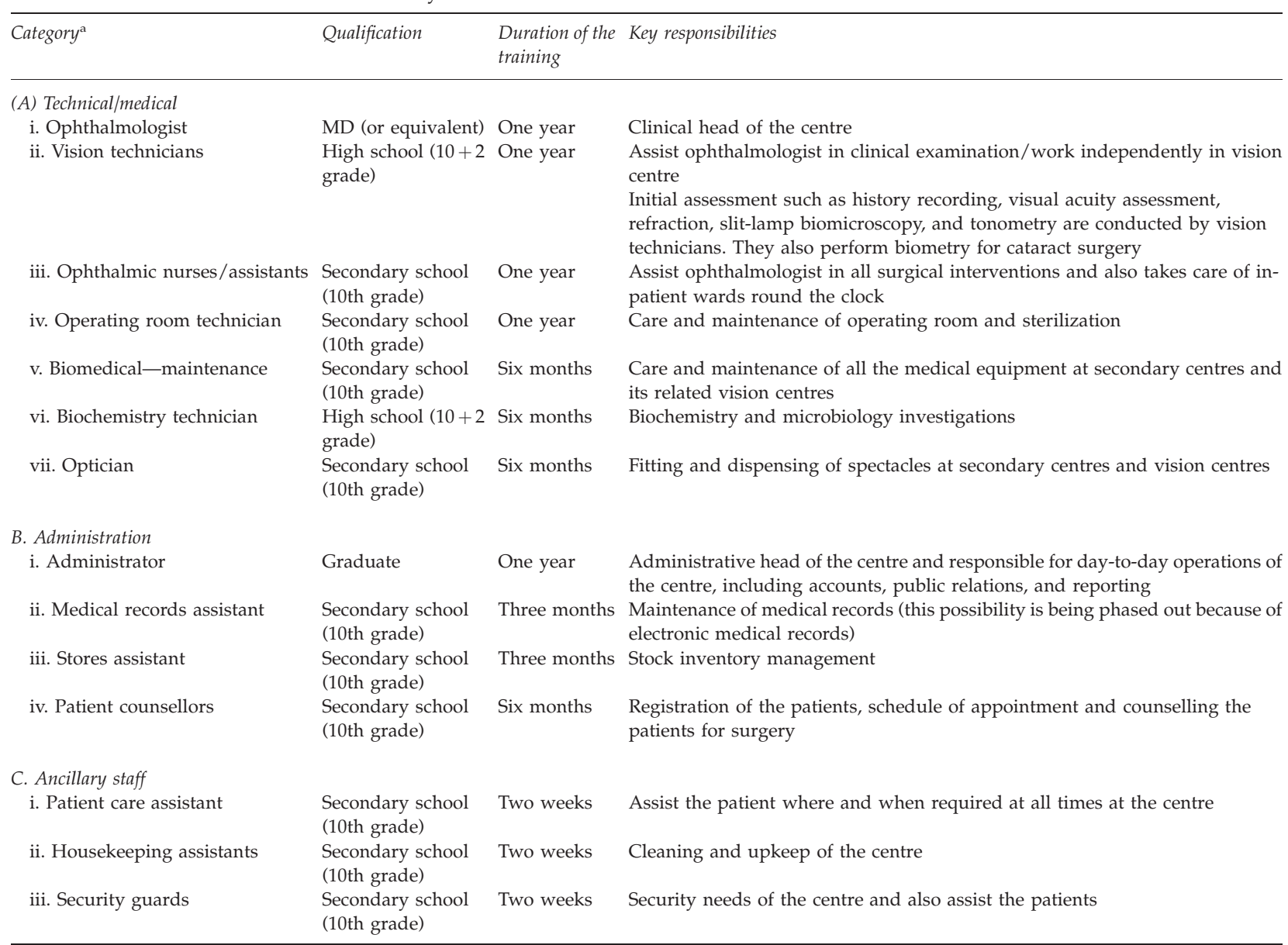

${ }^{a}$ All the staff except ophthalmologists are recruited from local communities.

visually impaired need to seek care from tertiary level centres.

These centres in LVPEI pyramid are developed to serve a population of 5-10 million, depending on the density and distances. Built at a cost of around USD 3.0 million, these centres are designed to service 100000 outpatients and perform 10000 surgical procedures annually by the end of 5 years. All the ophthalmic subspecialty services and low vision rehabilitation services are incorporated. All the ophthalmologists representing different subspecialties as well as optometrists with special training, covering different disciplines, and well-trained operating room staff form the core of the medical and technical team. This group is supported by robust administrative, support, and ancillary services.

In addition to tertiary level eye care services, these centres also offer education and training programmes to various cadres of eye care personnel. Clinical research and clinical trials form another activity of tertiary centres.
The major focus at this level is basic tertiary care combined with training. These centres form the base for the training programmes. Through the linkage with Secondary Centres in the geographic area, Tertiary Centres provide human resource, training, monitoring, and mentoring support to the Secondary and Vision Centres within their purview.

\section{Centre of excellence}

The topmost tier of the pyramidal model is a centre that has the overall responsibility of the entire network and maintaining the highest quality of standards practiced anywhere. Developed along the lines of the major eye centres around the world, it combines cutting-edge advanced tertiary care focussed on complex eye problems, education, and training for all cadres of eye care personnel, specifically training the trainers, along with doctoral and postdoctoral programmes and 


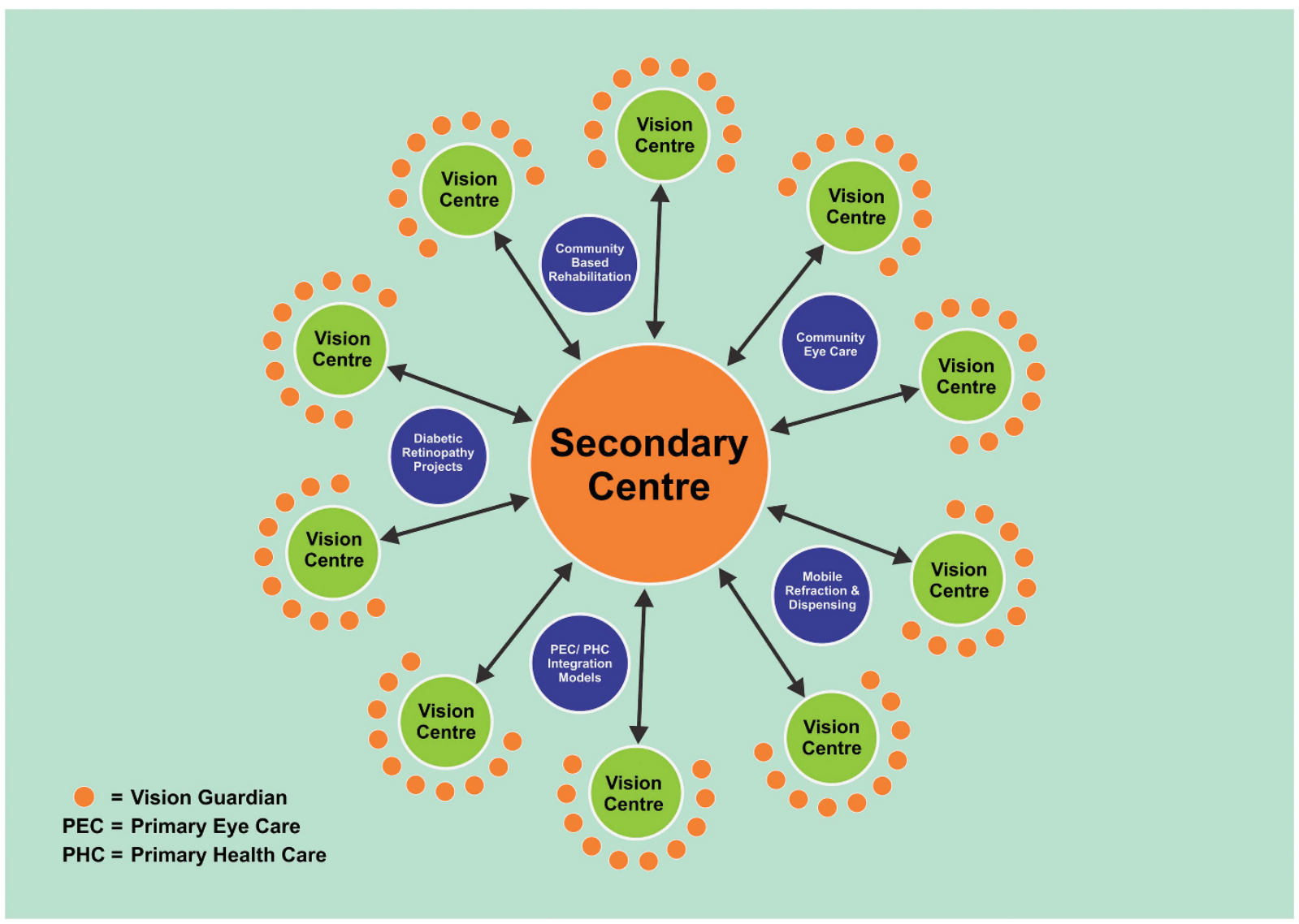

Figure 2 Schematic representation of L V Prasad Eye Institute's Village Vision Complex (VVC).

advanced research programmes. In addition, resource mobilization and contributing to advocacy and eye care policy at global and national levels is an essential role at this level.

While developing this centre, the epidemiologic information on blindness in India and the general socioeconomic profile that influence health care were taken into consideration. Various subspecialties and the support services were designed as per these requirements. Significant innovations were introduced in all aspects of planning that support the vision of reconciling 'Excellence with Equity'. A few of the examples of this endeavour are described here.

\section{Cornea service}

To address the enormous magnitude of corneal blindness in India and the fact that very few high-quality corneal services existed, a comprehensive Cornea and External Disease Service was initiated offering all services. About half the patients were treated at absolutely no cost to them whatever may be the complexity of care. Contact lens service, microbiology, and pathology laboratories helped immensely in providing optimal care.
Attention was paid to all factors that influence the outcome of corneal transplantation, namely, the quality of donor cornea, understanding the nature of recipient pathology, and the care elements that encompass the surgery, follow-up care, and visual rehabilitation. An international standard eye bank was developed with technical support from International Federation of Eye Banks of Baltimore, MD, USA, and all the specialists selected had appropriate training. To ensure follow-up care across the country (as our patients come from everywhere), training programmes were specially designed to increase the number of ophthalmologists who are exposed to the care of corneal transplants. Paying special attention to those from the neglected groups, facilities were created for additional days of hospital stay and support for follow-up care for these patients.

The Ramayamma International Eye Bank (RIEB) is now one of the biggest in the world with around 4500 corneas harvested and 2500 corneal transplants performed during the past year. Fellowship training has produced scores of corneal specialists who are now spread over all of the Indian subcontinent and many other developing countries. Nearly 50000 corneas were 
harvested and over 20000 corneal transplants performed with more corneas supplied to other surgeons. Indeed, our eye bank and cornea services have become a resource centre for India and other developing countries.

\section{Children's eye care centre}

As an area of focus, a comprehensive children's eye care centre was developed encompassing prevention programmes, treatment covering all problems and low vision rehabilitation. Certain special programmes made a significant impact.

Retinopathy of prematurity is increasingly becoming a cause of blindness among new borns in emerging economies, particularly where neonatal care units exist. While intensive ophthalmic surveillance of these new borns can prevent sight-threatening sequelae, many countries and regions fall short of these requirements, often leading to needless blindness. LVPEI has established a system of rigorous surveillance across all neonatal units in the city of Hyderabad and succeeded in controlling this malady. LVPEI is now expanding this model across the entire state of Andhra Pradesh through active training and is enhancing awareness among all the providers of care for children. In addition, working with the Government, the model is replicated in other cities.

Childhood glaucoma is another area where, through special attention, much progress was achieved through public awareness, parent support groups, and early diagnosis with prompt treatment.

India has the largest proportion of all new cases of retinoblastoma in the world. While it is known that early diagnosis and prompt treatment can save both the eye and the life of the affected, it can lead to significant disability and death if the victims do not access care at an early stage. A model 'Comprehensive Eye Cancer Centre' was set up to address this issue.

\section{Education and research}

The entire service element of LVPEI has the benefit of immense support from Education and Research components. The education centre ensures a regular pipeline of well-trained human resources of all cadres and provides monitoring and mentoring.

Our research centre covers a broad range in the field of eye and vision. Basic laboratory, clinical, visual psychophysics, translational, public health, and low vision research are the major components. The public health component has provided evidence through APEDS for the development of our eye care delivery model. Stem cell biology group invented a simple new technique, Simple Limbal Epithelial Transplant (SLET), that eliminates the need for a laboratory. The genetics group has identified the genetic basis for many conditions that will soon lead to newer approaches for therapy.

Education and research together produced many professionals and researchers of high caliber that added to capacity building in India and other developing countries.

\section{Rehabilitation services}

According to the World Health report on disability, people with disabilities have the same general healthcare needs as others. However, they are two times more likely to find health-care providers' skills and facilities inadequate, three times more likely to be denied health care and four times more likely to be treated badly in the health-care system. ${ }^{83}$

Rehabilitation services are an integral part of LVPEI. Technological and physical help is made available to those who need it. Indeed, LVPEI is one of the few eye care institutions anywhere in the world, where clinical care and rehabilitation are provided in the same campus. Rehabilitation is a combination of learning teaching in daily living and work-related skills, and the use of suitable low vision devices, along with professional counselling. LVPEI has a very active low vision rehabilitation programme and this is also replicated in the tertiary centres. These vision rehabilitation centres have collaborative links with both international and national organizations, working to help realize the full potential of each individual.

The presence of this service allows LVPEI to provide comprehensive eye care to all age groups affected with diverse eye problems not correctable by medical or surgical therapy.

\section{Sustainability}

While sustainability has many elements, chief among them are human and financial. Sustainability of human resources is ensured in this model through a fairly systematic approach to training, recruitment, career advancement, and fair compensation. In addition, the satisfaction of 'doing good' and the reputation of the brand are other important factors in retention. A very robust education and training programme provides a pipeline of well-trained professionals.

\section{Financial sustainability}

LVPEI has followed simple principles of financial management: 
All operating expenses are met by revenues from patient care, fees from education programmes and competitive grants.

$\checkmark$ Cross-subsidization is the strategy adopted to provide care to more than $50 \%$ of patients at no cost to them.

Capital expenses and new projects are met with income from grants, a philanthropy, royalties, and income from optical and pharmacy businesses.

Endowment is built with a portion of the funds from the latter group.

No bank loans or overdraft of pending payments.

\section{Role of technology and innovation}

The world has witnessed revolutionary progress in information and communication technology and engineering, which offer hope of enhancing access and quality of health care to the most neglected communities. However, the prohibitive cost is a barrier for employment of such technologies at present. Innovations addressing this at many places, notably in the media laboratory of Massachusetts Institute of Technology, offer hope. In collaboration with this group, LVPEI has initiated an innovation centre where scores of engineering, technology, and design students from across India are engaged in exciting innovations. Such endeavours present an optimistic outlook for availability and accessibility of health care to the most neglected communities. When these are combined with appropriately trained human resources as in the case of LVPEI, elimination of avoidable blindness seems a distinct possibility.

\section{Conclusions and remarks}

High-quality, comprehensive eye care that is equitable and sustainable is the aspiration of all involved in eye care globally and is the core aim of VISION 2020: The Right to Sight. From the available information and experiences around the world, the development of a framework to realize this, with strong linkages across multiple levels of care and integration with other healthcare systems, is the key to eliminate avoidable blindness. Proper planning together with implementation, using appropriate infrastructure, well-trained human resources, and efficient operating systems can yield the desired results. Strong advocacy efforts are required to make necessary resources available, and for prevention of blindness and eye care to get due prioritization.

LVPEI pyramidal model is an illustration of 'Universal Health Coverage'. Several facets of this model may be considered for replication globally both in eye care and other areas of health care. Greater involvement of major eye care centres as well as major organizational and professional groups across the world in such endeavours may accelerate our journey towards elimination of needless blindness globally.

\section{Conflict of interest}

The author declares no conflict of interest.

\section{Acknowledgements}

All the work presented in this article is the cumulative effort of a dedicated and diligent team at L V Prasad Eye Institute. Srinivas Marmamula's help in preparing this manuscript is gratefully acknowledged. My special thanks to Sreedevi Penmetcha for the many ways in which she facilitated preparation of the manuscript in a timely manner. Special appreciation to Vaidya Gullapalli and Sreedevi Yadavalli who improved the manuscript with their editing.

\section{References}

1 Watts G. Barrie Russell Jones. Lancet 2009; 374(9701): 1590.

2 McKinsey Global Institute. India's Path from Poverty to Empowerment. McKinsey Global Institute: India, 2012.

3 Ulldemolins AR, Lansingh VC, Valencia LG, Carter MJ, Eckert KA. Social inequalities in blindness and visual impairment: a review of social determinants. Indian J Ophthalmol 2012; 60(5): 368-375.

4 Khanna R, Raman U, Rao GN. Blindness and poverty in India: the way forward. Clin Exp Optom 2007; 90(6): 406-414.

5 Dandona R, Dandona L. Socioeconomic status and blindness. Br J Ophthalmol 2001; 85(12): 1484-1488.

6 Brilliant GE, Lepkowski JM, Zurita B, Thulasiraj RD. Social determinants of cataract surgery utilization in south India. The Operations Research Group. Arch Ophthalmol 1991; 109(4): 584-589.

7 Dandona R, Dandona L, Naduvilath TJ, McCarty CA, Rao GN. Utilisation of eyecare services in an urban population in southern India: the Andhra Pradesh Eye Disease Study. Br J Ophthalmol 2000; 84(1): 22-27.

8 Finger RP. Cataracts in India: current situation, access, and barriers to services over time. Ophthalmic Epidemiol 2007; 14(3): 112-118.

9 Fletcher AE, Donoghue M, Devavaram J, Thulasiraj RD, Scott S, Abdalla $\mathrm{M}$ et al. Low uptake of eye services in rural India: a challenge for programs of blindness prevention. Arch Ophthalmol 1999; 117(10): 1393-1399.

10 Kovai V, Krishnaiah S, Shamanna BR, Thomas R, Rao GN. Barriers to accessing eye care services among visually impaired populations in rural Andhra Pradesh, South India. Indian J Ophthalmol 2007; 55(5): 365-371.

11 Marmamula S, Keeffe JE, Raman U, Rao GN. Populationbased cross-sectional study of barriers to utilisation of refraction services in South India: Rapid Assessment of Refractive Errors (RARE) Study. BMJ Open 2011; 1(1): e000172. 
12 Vaidyanathan K, Limburg H, Foster A, Pandey RM. Changing trends in barriers to cataract surgery in India. Bull World Health Organ 1999; 77(2): 104-109.

13 The resolution of the world health assembly on the elimination of avoidable blindness. Community Eye Health 2003; 16(46): 18

14 56.26 WR. WHA Resolution 56.26. WHO: Geneva, Switzerland. Available at http://apps.who.int/gb/archive/ pdf files/WHA56/ea5626.pdf (last accessed 14 May 2014).

15 59.25 WR. WHA Resolution 59.25. WHO: Geneva, Switzerland. Available at http:/ /apps.who.int/gb/archive/ e/e wha59.html (last accessed 14 May 2014).

16 62.1 WR. WHA Resolution 62.1. WHO : Geneva, Switzerland Available at http://apps.who.int/gb/ebwha/pdf_files/ A62/A62_1Rev1-en.pdf (last accessed 14 May 2014).

17 World Health Organization. Primary Health Care-Now More than Ever. WHO: Geneva, Switzerland 2008

18 Planning Commission of India. High Level Expert Group Report on Universal Health Coverage for India. Planning Commission of India: New Delhi, India, 2011.

19 Stevens GA, White RA, Flaxman SR, Price H, Jonas JB, Keeffe J et al. Global prevalence of vision impairment and blindness: magnitude and temporal trends, 1990-2010. Ophthalmology 2013; 120(12): 2377-2384.

20 Bourne RRA, Stevens GA, White RA, Smith JL, Flaxman SR, Price $\mathrm{H}$ et al. Causes of vision loss worldwide, 1990-2010: a systematic analysis. Lancet Global Health 2013; 1(6): e339-e349.

21 Resnikoff S, Pararajasegaram R. Blindness prevention programmes: past, present, and future. Bull World Health Organ 2001; 79(3): 222-226.

22 UNICEF. Vitamin A Supplementation: A Decade of Progress. UNICEF: New York, NY, USA, 2007.

23 WHO. Micronutrient Deficiencies-Vitamin A. WHO: Geneva, Switzerland, Available at http://www.who.int/ nutrition/topics/vad/en/ (last accessed 25 April 2014).

24 Amazigo U. The African Programme for Onchocerciasis Control (APOC). Ann Trop Med Parasitol 2008; 102(Suppl 1): 19-22.

25 Coffeng LE, Stolk WA, Zoure HG, Veerman JL, Agblewonu KB, Murdoch ME et al. African Programme for Onchocerciasis Control 1995-2015: model-estimated health impact and cost. PLoS Negl Trop Dis 2013; 7(1): e2032.

26 Colatrella B. The Mectizan Donation Program: 20 years of successful collaboration-a retrospective. Ann Trop Med Parasitol 2008; 102(Suppl 1): 7-11.

$27 \mathrm{Hu}$ VH, Harding-Esch EM, Burton MJ, Bailey RL, Kadimpeul J, Mabey DC. Epidemiology and control of trachoma: systematic review. Trop Med Int 2010; 15(6): 673-691.

28 Wright HR, Turner A, Taylor HR. Trachoma. Lancet 2008; 371(9628): 1945-1954

29 Ackland P. The accomplishments of the global initiative VISION 2020: the right to sight and the focus for the next 8 years of the campaign. Indian J Ophthalmol 2012; 60(5): 380-386.

30 Centers for Disease C, Prevention. Progress toward elimination of onchocerciasis in the Americas-1993-2012. Morb Mort Weekly Rep 2013; 62(20): 405-408.

31 Diawara L, Traore MO, Badji A, Bissan Y, Doumbia K, Goita SF et al. Feasibility of onchocerciasis elimination with ivermectin treatment in endemic foci in Africa: first evidence from studies in Mali and Senegal. PLoS Negl Trop Dis 2009; 3(7): e497.
32 Meredith SE, Cross C, Amazigo UV. Empowering communities in combating river blindness and the role of NGOs: case studies from Cameroon, Mali, Nigeria, and Uganda. Health Res Policy Syst 2012; 10: 16.

33 WHO. Global WHO alliance for the elimination of blinding trachoma by 2020. Releve epidemiologique hebdomadaire/ Section d'hygiene du Secretariat de la Societe des Nations = Weekly epidemiological record / Health Section of the Secretariat of the League of Nations 2012; 87(17): 161-168.

34 Baltussen R, Sylla M, Mariotti SP. Cost-effectiveness analysis of cataract surgery: a global and regional analysis. Bull World Health Organ 2004; 82(5): 338-345.

35 Lansingh VC, Carter MJ, Martens M. Global costeffectiveness of cataract surgery. Ophthalmology 2007; 114(9): 1670-1678.

36 Blanchet K, Gordon I, Gilbert CE, Wormald R, Awan H. How to achieve universal coverage of cataract surgical services in developing countries: lessons from systematic reviews of other services. Ophthal Eepidemiol 2012; 19(6): 329-339.

37 Khanna R, Pujari S, Sangwan V. Cataract surgery in developing countries. Curr Opin Ophthalmol 2011; 22(1): $10-14$.

38 Qureshi BM, Mansur R, Al-Rajhi A, Lansingh V, Eckert K, Hassan $\mathrm{K}$ et al. Best practice eye care models. Indian J Ophthalmol 2012; 60(5): 351-357.

39 Rao GN, Khanna RC, Athota SM, Rajshekar V, Rani PK. Integrated model of primary and secondary eye care for underserved rural areas: the L V Prasad Eye Institute experience. Indian J Ophthalmol 2012; 60(5): 396-400.

40 Lewallen S, Thulasiraj RD. Eliminating cataract blindnesshow do we apply lessons from Asia to sub-Saharan Africa? Global Public Health 2010; 5(6): 639-648

41 Natchiar G, Robin AL, Thulasiraj RD, Krishnaswamy S. Attacking the backlog of India's curable blind. The Aravind Eye Hospital model. Arch Ophthalmol 1994; 112(7): 987-993.

42 Dandona L, Dandona R, Anand R, Srinivas M, Rajashekar V. Outcome and number of cataract surgeries in India: policy issues for blindness control. Clin Exp Ophthalmol 2003; 31(1): 23-31.

43 Khanna RC, Pallerla SR, Eeda SS, Gudapati BK, Cassard SD, Rani PK et al. Population based outcomes of cataract surgery in three tribal areas of Andhra Pradesh, India: risk factors for poor outcomes. PLoS One 2012; 7(5): e35701.

44 Lindfield R, Vishwanath K, Ngounou F, Khanna RC. The challenges in improving outcome of cataract surgery in low and middle income countries. Indian J Ophthalmol 2012; 60(5): 464-469.

45 Thomas R, Paul P, Rao GN, Muliyil JP, Mathai A. Present status of eye care in India. Surv Ophthalmol 2005; 50(1): 85-101.

46 Jose R, Bachani D. World Bank-Assisted Cataract Blindness Control Project. Indian J Ophthalmol 1995; 43(1): 35-43.

47 Jose R, Rathore AS, Rajshekar V, Sachdeva S. Salient features of the National Program for Control of Blindness during the XIth five-year plan period. Indian J Ophthalmol 2009; 57(5): 339-340.

48 NPCB. Government of India. Available at http://npcb. nic.in/writereaddata/mainlinkfile/File292.pdf (last accessed 30 April 2014).

49 Naidoo KS, Jaggernath J. Uncorrected refractive errors Indian J Ophthalmol 2012; 60(5): 432-437. 
50 VisionSpring. Available at http://visionspring.org/ (last accessed 6 May 2014).

51 IAPB. Refractive Error Working Commitee Document. IAPB: Australia, 2008

52 Murthy KR, Murthy PR, Kapur A, Owens DR. Mobile diabetes eye care: experience in developing countries. Diabetes Res Clin Pract 2012; 97(3): 343-349.

53 Rani PK, Raman R, Sharma V, Mahuli SV, Tarigopala A, Sudhir RR et al. Analysis of a comprehensive diabetic retinopathy screening model for rural and urban diabetics in developing countries. Br J Ophthalmol 2007; 91(11): 1425-1429.

54 Zheng Y, He M, Congdon N. The worldwide epidemic of diabetic retinopathy. Indian J Ophthalmol 2012; 60(5): 428-431.

55 Thomas R. Glaucoma in developing countries. Indian J Ophthalmol 2012; 60(5): 446-450.

56 Thomas R, Naveen S, Nirmalan P, Parikh R. Detection of ocular disease by a vision center technician and the role of frequency doubling technology perimetry in this setting. Br J Ophthalmol 2009; 94: 214-218.

57 Gilbert C. Changing challenges in the control of blindness in children. Eye 2007; 21(10): 1338-1343.

58 Gilbert C, Foster A. Childhood blindness in the context of VISION 2020-the right to sight. Bull World Health Organ 2001; 79(3): 227-232.

59 Dandona R, Dandona L, Srinivas M, Giridhar P, Nutheti R, Rao GN. Planning low vision services in India: a population-based perspective. Ophthalmology 2002; 109(10): 1871-1878.

60 Ryan B. Models of low vision care: past, present and future. Clin Exp Optom 2014; 97(3): 209-213.

61 Chiang PP, O'Connor PM, Le Mesurier RT, Keeffe JE. A global survey of low vision service provision. Ophthal Epidemiol 2011; 18(3): 109-121.

62 Agarwal LP. National programme for prevention of visual impairment and control of blindness. Indian J Ophthalmol 1978; 25(4): 1-5.

63 Murthy GV, Gupta SK, Bachani D, Jose R, John N. Current estimates of blindness in India. Br J Ophthalmol 2005; 89(3): 257-260.

64 Neena J, Rachel J, Praveen V, Murthy GV. Rapid Assessment of Avoidable Blindness India Study G. Rapid assessment of avoidable blindness in india. PLoS One 2008; 3(8): e2867.

65 Bachani D, Murthy GV, Gupta KS. Rapid assessment of cataract blindness in India. Indian J Public Health 2000; 44(3): $82-89$.

66 Murthy G, Gupta SK, John N, Vashist P. Current status of cataract blindness and Vision 2020: the right to sight initiative in India. Indian J Ophthalmol 2008; 56(6): 489-494.

67 Dandona R, Dandona L, Naduvilath TJ, Nanda A, McCarty CA. Design of a population-based study of visual impairment in India: The Andhra Pradesh Eye Disease Study. Indian J Ophthalmol 1997; 45(4): 251-257.
68 Dandona L, Dandona R, Srinivas M, Giridhar P, Vilas K, Prasad MN et al. Blindness in the Indian state of Andhra Pradesh. Invest Ophthalmol Vis Sci 2001; 42(5): 908-916.

69 Dandona R, Dandona L, Srinivas M, Giridhar P, Prasad MN, Vilas $\mathrm{K}$ et al. Moderate visual impairment in India: the Andhra Pradesh Eye Disease Study. Br J Ophthalmol 2002; 86(4): 373-377.

70 Dandona R, Dandona L, Srinivas M, Giridhar P, McCarty CA, Rao GN. Population-based assessment of refractive error in India: the Andhra Pradesh Eye Disease Study. Clin Exp Ophthalmol 2002; 30(2): 84-93.

71 Dandona R, Dandona L, Kovai V, Giridhar P, Prasad MN, Srinivas M. Population-based study of spectacles use in southern India. Indian J Ophthalmol 2002; 50(2): 145-155.

72 Rao GN. An infrastructure model for the implementation of VISION 2020: the right to sight. Can J Ophthalmol 2004; 39: 589-594.

73 Kuruganti S, Mekala J, Williams JD, Krishnaiah S, Rao GN, Rani PK. Preventive eye health approach and elimination of avoidable blindness in remote rural areas - a vision health guardian approach. Rural Remote Health 2012; 12: 1912.

74 Kovai V, Rao GN, Holden B. Key factors determining success of primary eye care through vision centres in rural India: patients' perspectives. Indian J Ophthalmol 2012; 60(5): 487-491.

75 Kovai V, Rao GN, Holden B, Sannapaneni K, Bhattacharya SK, Khanna R. Comparison of patient satisfaction with services of vision centers in rural areas of Andhra Pradesh, India. Indian J Ophthalmol 2010; 58(5): 407-413.

76 Dandona L, Dandona R, Shamanna BR, Naduvilath TJ, Rao GN. Developing a model to reduce blindness in India: The International Centre for Advancement of Rural Eye Care. Indian J Ophthalmol 1998; 46(4): 263-268.

77 System AECAravind Eye Care System. Available at http://www.aravind.org/communityoutreach/ primaryeyecarecentres.aspx (last accessed 30 April 2014) 2014.

78 Vijayakumar V. Primary eye care services through IT enabled vision centres. ACES, Illumination 2013; 12(2): 12-15.

79 PremAnand S. Vision Centre Program-Tripura, A TeleOphthalmology Project. Team ILEFS-Health Initiat Available at http://www.cips.org.in/public-sectorsystems-government-innovations/documents/TripuraTelemedicine-Initiative.pdf (last accessed 6 May 2014).

80 Sudhan A. 'Vision Centre' as a strategy to provide eye care services to underserved populations: results from Satna district of Madhya Pradesh, India. J Community Eye HealthIndian Suppl 2008; 21(68): 117-118.

81 BHV InstituteVision Centre Development. Available at http:/ / www.brienholdenvision.org/global-eye-care/ vision-centre-development.html (last accessed 6 May 2014) 2014.

82 Shamanna BR, Nirmalan PK, Saravanan S. Roles and responsibilities in the secondary level eye care model. Community Eye Health/Int Centre Eye Health 2005; 18(56): 120-121.

83 WHO. World Report on Disability. WHO, 2011. 